\title{
OCCUPATIONAL POSITION AND ALCOHOL USE DISORDERS IN POLAND
}

\section{MICHAŁ BUJALSKI, JACEK MOSKALEWICZ, and JAKUB STOKWISZEWSKI}

Institute of Psychiatry and Neurology, Warsaw, Poland

Department of Studies on Alcoholism and Drug Dependencies

\begin{abstract}
Objectives: The following analysis covers the role of the occupational structure in the prevalence of alcohol use disorders (AUDs). The authors investigated whether the occupational position affected the prevalence of AUDs among men and women, and how this relationship varied in lifetime and past year periods. Material and Methods: Data were taken from the General Population Survey on Mental Health in Poland (EZOP) utilizing the Composite International Diagnostic Interview questionnaire $(\mathrm{N}=2806)$. Binary and multiple regression models were employed to assess the risk of AUDs adjusted for the occupational structure and socio-demographic variables. Results: The occupational position affects the prevalence of AUDs in men, while it has no impact on AUDs in women. Skilled and non-skilled workers suffer from AUDs to a greater extent than those in higher occupational positions. However, the risk of alcohol harm in women seems to be equally distributed across the occupational structure. Conclusions: The uneven pattern of alcohol harm in men and women can be possibly explained by shifting working conditions and work environments, as well as traditional gender roles affecting alcohol behaviors. The findings of the study support further development of the occupational position concept in alcohol research. The problem of harmful alcohol drinking in women across the occupational structure warrants a more in-depth inquiry. Int J Occup Med Environ Health. 2021;34(5):591-602
\end{abstract}

Key words:

alcohol, Poland, gender, occupational status, alcohol use disorders, occupational structure

\section{INTRODUCTION}

Alcohol use disorders (AUDs) generate social and health problems on both individual and collective levels, including violence, child neglect, low productivity, psychological distress, several acute and long-term health problems, as well as addiction [1,2]. A lifetime harmful use of alcohol accounts for $11.9 \%$ of the working age population in Poland which translates into around 3 million individuals, among whom $2.4 \%$ meet the diagnostic criteria of alcohol dependence [3]. Alcohol problems affect mostly men, $20.5 \%$ of whom abuse alcohol while $4.4 \%$ have been diagnosed as alcohol dependent. Alcohol problems affect women to a far lesser extent in all age groups - only 3.4\% of all women abuse alcohol. Most of the women who abuse alcohol have a university degree, contrary to men with primary or vocational education drinking more extensively [3].

The debate on alcohol harm in Poland tends to be largely depoliticized and neglects a perspective of the social structure $[4,5]$. The highly individualized and medicalized problematization of harmful alcohol consumption corresponds to a liberal approach in public health and market developments, as well as affects the collective beliefs and perceptions of alcohol drinking [6,7].

Funding: this study was supported by the EEA and Norway Grants (grant No. PL0256 entitled "Epidemiology of Mental Disorders and Access to Care - EZOP Poland," project manager: Jacek Moskalewicz, Ph.D.) and by the Polish Ministry of Health (project No. E030/PO1/2008/02/85 entitled "Epidemiologia zaburzeń psychiatrycznych i dostępność psychiatrycznej opieki zdrowotnej EZOP-Polska," project manager: Jacek Moskalewicz, Ph.D.).

Received: September 22, 2020. Accepted: December 11, 2020.

Corresponding author: Michał Bujalski, Institute of Psychiatry and Neurology, Department of Studies on Alcoholism and Drug Dependencies, Sobieskiego 9, 02-957 Warsaw, Poland (e-mail: bujalski@ipin.edu.pl). 
The role of the social structure and occupational status in the prevalence of AUDs in Poland is often ignored. This particular kind of omission takes place despite the bulk of scientific literature on the role of socio-economic inequalities in the prevalence of alcohol problems and well-being.

A few studies show that populations at lower socio-economic positions experience greater alcohol-related problems and harm, including morbidity and mortality [8-11]. People with a low socio-economic status are more likely to suffer from alcohol-related diseases but they are also more likely to be either abstainers or heavy drinkers [12-14]; yet the question of the relationship between the social class and alcohol problems is ambiguous, and the problem of whether the socio-economic status has an independent effect on alcohol harm remains unsolved [11,12,15]. The inconsistent pattern of alcohol harm has been often reported in women. While some studies have shown that women representing higher social classes drink more frequently but extensive alcohol use is usually higher in lower occupational groups women [16,17], other studies report higher rates of heavy episodic drinking among women with a high socio-economic status [18,19].

A prevailing body of literature tends to investigate the relationship between occupational positions and alcohol problems in terms of general morbidity, mortality or risky drinking, rather than AUDs [20-25]. The current study intends to contribute to the ongoing discussion on the social class and occupational position as risk factors of harmful alcohol consumption [20,23,26,27] by utilizing the data on AUDs in the Polish adult population. The authors used occupational categories as determinants of social classes, as general occupational categories in Poland are considered to mirror the positions in the social structure and the distribution of access to resources, lifestyles, and attitudes $[28,29]$. The occupational status is based on a hierarchical structure reflecting the incomes, autonomy, respon- sibility [30], and, to some extent, also prestige [31]. The division of occupational positions also affects consumption patterns [32], as well as drinking and eating habits among Poles [33].

The aim of this investigation was to increase the current knowledge about the extent to which the occupational position affects the prevalence of AUDs and how this relationship varies in lifetime and past year periods. The authors also sought to find out whether the occupational position has the same impact on AUDs in men and women.

\section{MATERIAL AND METHODS}

Data were taken from the 2010 General Population Survey on Mental Health in Poland (EZOP) utilizing the Composite International Diagnostic Interview (CIDI) questionnaire [34-36]. The study sample was randomly drawn from the population register and consisted of 10081 respondents aged 18-64. All inhabitants who were entered to the register were included in the sampling. The sample was representative of all inhabitants of Poland of that age. A response rate of $50.4 \%$ was achieved. During the field work, however, those who suffered from organic disabilities and, therefore, could not understand the questions posed were excluded.

Due to its complexity and volume, the CIDI questionnaire was divided into several specialized paths covering various psychiatric diagnoses [37]. Questions covering alcohol diagnoses were addressed to 4001 respondents. About half of them were individuals diagnosed in the course of the study as having any mental health disorder; the remaining half were randomly selected from those in whom no mental health diagnosis was established. In the following analysis, 2806 respondents who provided information on their occupational position were included. All interviews were conducted using the computer-assisted personal interview (CAPI) method. Invitation letters were sent by post and the respondents received a free wall calendar for participating in the survey. 


\section{Outcome variables}

Two types of AUDs were investigated in the study, i.e., alcohol dependence and alcohol abuse, both defined according to the Diagnostic and Statistical Manual of Mental Disorders (DSM-IV) criteria. Both diagnoses were made for each study participant covering the periods of a lifetime and 12 months prior to the study. For the purposes of the following analysis, records of alcohol dependence and alcohol abuse were merged into the outcome variables identified as AUDs. In fact, all but 4 respondents with alcohol dependence confirmed alcohol abuse criteria.

\section{Predictor variables}

The authors' interest was mainly the role of the occupational position in the prevalence of AUDs. The pattern of the occupational structure was created according to the Polish Central Statistical Office. However, due to the recent dynamics in the upper white-collar class [12-13], the Polish Central Statistical Office' default pattern was further transformed; categories of managers and professionals, as well as technicians and office workers, were merged into 2 separate categories: managers and professionals, and semi-professionals, which eventually resulted in a pattern of 6 "large" occupational classes:

- managers and professionals: individuals holding managerial and executive positions, senior officials, professionals (science and engineering, health, business, administration, technology, information, communication sector, etc.);

- semi-professionals: technicians and associate professionals, office workers;

- employees in services: service and sales workers;

- agricultural workers: farmers, skilled agricultural, forestry and fishery workers;

- skilled workers: craftsmen, plant and machine operators and assemblers;

- non-skilled workers: elementary occupations and menial workers.
The respondents indicated their current employment status using a list of occupational categories, which were subsequently recoded into the above "large" categories for the purposes of this analysis. Those who were unemployed, retired or on pension during the study reported their most recent employment. Those who were never employed were excluded. The unemployment was controlled by a binary indicator added to the model. The socio-demographic variables used in the analysis covered gender, age groups (18-29 years, 30-39 years, 40-49 years, 50-64 years), education (primary, vocational, secondary, university), and the place of residence (a rural area, a city with $<50000$ inhabitants, a city with $50000-200000$ inhabitants, a city with $>200000$ inhabitants).

\section{Statistical analyses}

The authors used weighted data, based on the information provided by the Polish Central Statistical Office comprising the socio-demographic factors controlled in the study (the distribution of gender, age, and the place of residence). In the first step of the analysis, the odd ratios (OR) with 95\% confidence intervals (CI) for AUDs (lifetime and 12 months prior to the study) were estimated for each of the explanatory variables groups, as well as for occupational positions. These univariate regression analyses were conducted to identify the robust predictors of the outcome variable for men and women separately.

In the second step, all significant predictors were added to multiple regression models. As a result, 2 regression models were developed for each gender separately, adjusted to the age group, education, the place of residence and the employment status. Predictor variables were checked for multicollinearity by calculating variance inflation factors (VIFs). The average VIF for men was 1.253, and the maximum VIF was 1.595 (education), while the average VIF for women was 1.328, and the maximum VIF was 1.771 (education). Since the VIFs for the current set of variables were $<2$, it was contended that no multicollinearity was present. All the analyses were conducted with IBM SPSS v21. 


\section{RESULTS}

Table 1 reports the characteristics of the study sample. There are clear gender differences across the occupational groups. The top occupational group - managers and professionals - were mostly men holding a university degree. Semi-professionals and employees in services were mostly women with completed secondary education. Agricultural workers, skilled workers, and the lowest occupational group, i.e., non-skilled workers, were mostly men with vocational education. Finally, $11 \%$ of the sample were unemployed, most of whom were found among non-skilled workers.

Lifetime AUDs were unevenly distributed among occupational classes, and they were mostly found among skilled and non-skilled workers (Table 2). In fact, AUDs were the least common among semi-professionals and employees in services, and relatively more prevalent among managers and professionals. The data covering 12 months prior to the survey show a more flattened distribution of AUDs, with skilled and non-skilled workers most often experiencing alcohol disorders. When exploring gender differences, skilled and non-skilled workers seem to be more vulnerable to AUDs among men, while among women it is the top managers and professionals' class that experienced lifetime and 12 months AUDs more often than any other occupational category.

The calculated OR values for the socio-demographic variables in men and women (Table 3) show a higher risk of both lifetime $(\mathrm{OR}=7.286)$ and past 12 months $(\mathrm{OR}=$ 10.372) prevalence of AUDs for men (not reported in the table), and a higher lifetime risk for both men and women who were currently unemployed. Older age male cohorts have a higher risk of lifetime AUDs. Both the lifetime and 12 months prevalence was lower among men with secondary education compared to those having primary education. The lifetime AUDs risk was also higher for men and women living in large cities compared to the inhabitants of rural areas. Given the substantial impact of gender on the AUDs prevalence across occupational cat- egories and a low number of women, the authors decided to design 2 separate models of multiple logistic regression for men and women. In women, they also gave up the past 12 months prevalence model and merged non-skilled and skilled workers into the lifetime model due to a relatively low number of cases (Table 2).

Table 4 presents the OR values for multiple logistic regression in men, adjusted for the employment status and sociodemographic variables. The occupational position is a significant predictor of AUDs in lifetime and past 12 months showing the inverse gradual trend in the AUDs risk from the top of the occupational structure, with the exception of agricultural workers in the past 12 months prevalence. Those who reported being unemployed were at a higher risk of AUDs. Men in their forties showed an increased prevalence of lifetime AUDs. The inhabitants of large and small cities had an increased risk of lifetime AUDs compared to the inhabitants of rural areas, while the OR values for the past 12 months prevalence of AUDs were 3 times higher among men living in large cities than among those living in rural areas. The lifetime prevalence model explained $9 \%$, while the past 12 months model accounted for $13 \%$, of the variance.

The OR values for AUDs in women can be found in Table 4. No differences in the AUDs prevalence were found among occupational positions. Unemployed women showed an increased risk of the lifetime prevalence of AUDs. The risk of experiencing the lifetime prevalence of AUDs was more than twice as high in women living in large cities as in those living in rural areas. There was no statistically significant impact of the interaction between education and occupational categories, as well as between the place of residence and occupational categories (not reported in the table).

\section{DISCUSSION}

In this study, the authors investigated the relationship between occupational categories and AUDs. Their results suggest a gender-patterned impact of occupational posi- 


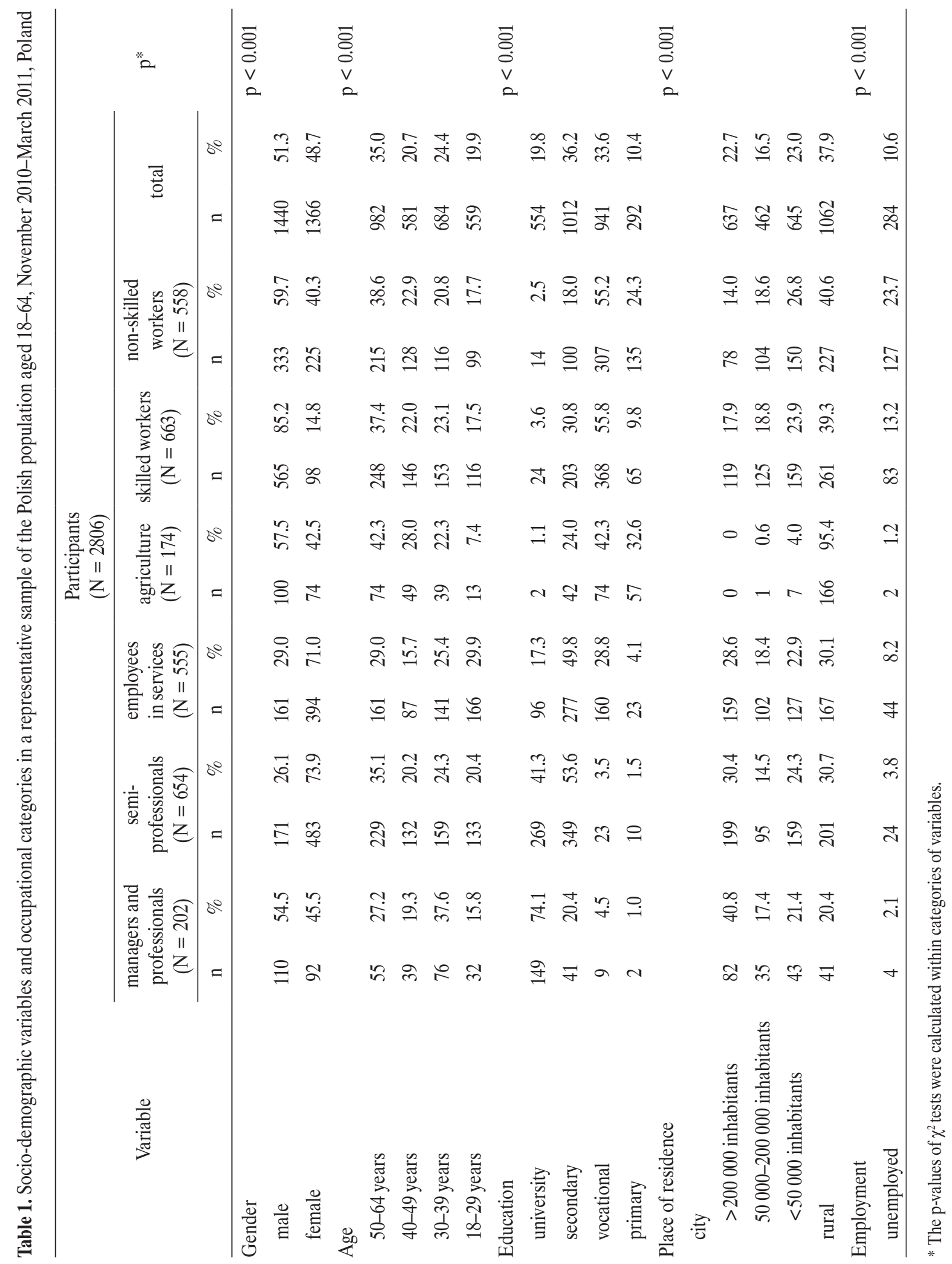




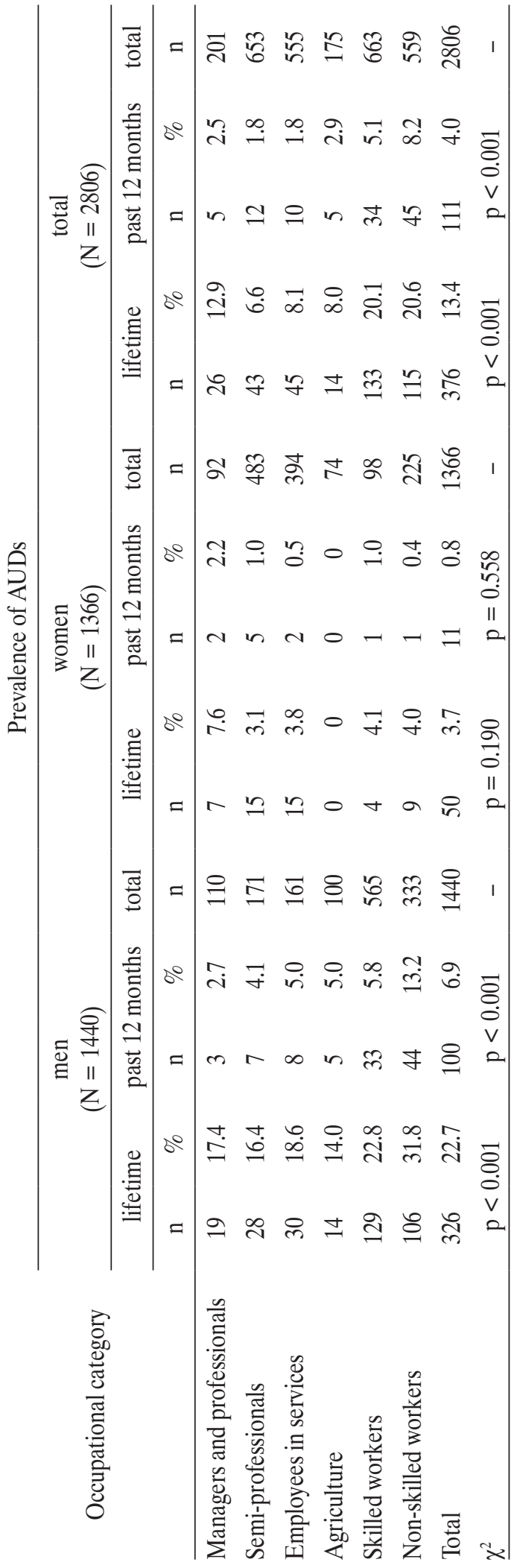

tions on the prevalence of AUDs in Poland. The results of the regression models adjusted to socio-demographic variables show an inverse gradual gradient of the AUDs prevalence in the occupational categories in men: each higher occupational class had a reduced risk of AUDs compared to the lowest class of non-skilled workers. The impact of the occupational position was confirmed in both the lifetime and past 12 months diagnoses of AUDs with the exception of agricultural workers who showed no differences in comparison to non-skilled workers in the past 12 months prevalence.

The occupational position proved to have no effect on AUDs in women. The authors also found unemployment to be a substantial factor for the lifetime and past 12 months prevalence of AUDs in men, but only for the lifetime prevalence in women. The effect of the occupational category is further amplified by the place of residence as the inhabitants of large cities were generally at a higher risk of AUDs. The outcomes were not affected by education. Generally, it can be concluded that male non-skilled and agricultural workers are at a higher risk of experiencing lifetime alcohol problems.

Although being out of the labor market was found to play a significant role in the AUDs prevalence, it cannot be unambiguously concluded that unemployment affects AUDs, as the authors were unable to find out which one preceded another. The impact of unemployment on the lifetime prevalence of AUDs is even more troubling to investigate; however, a clear link between these 2 items has been proven to exist.

The results are consistent with the authors' initial assumptions that individuals in higher occupational positions have more abilities to overcome alcohol dependence and abuse. An essential reason for the above outcome might be the interplay of the social, cultural and economic capital which makes those in higher positions simply better equipped in going through the hardships of everyday life. Another explanation can be possibly found in shifting 
Table 3. Univariate logistic regression for alcohol use disorders (AUDs) in occupational and socio-demographic categories in a representative sample of the Polish population aged 18-64, November 2010-March 2011, Poland

\begin{tabular}{|c|c|c|c|c|c|c|}
\hline \multirow{4}{*}{ Variable } & \multicolumn{6}{|c|}{ Prevalence of AUDs - univariate logistic regression } \\
\hline & \multicolumn{4}{|c|}{$\begin{array}{c}\text { men } \\
(\mathrm{N}=1440)\end{array}$} & \multirow{2}{*}{\multicolumn{2}{|c|}{$\begin{array}{c}\text { women } \\
(\mathrm{N}=1366) \\
\text { lifetime }\end{array}$}} \\
\hline & \multicolumn{2}{|c|}{ lifetime } & \multicolumn{2}{|c|}{ past 12 months } & & \\
\hline & OR & $95 \% \mathrm{CI}$ & OR & $95 \% \mathrm{CI}$ & OR & $95 \% \mathrm{CI}$ \\
\hline \multicolumn{7}{|l|}{ Occupational category } \\
\hline managers and professionals & $0.459^{* *}$ & $0.267-0.790$ & $0.166^{* *}$ & $0.048-0.577$ & 1.919 & $0.691-5.325$ \\
\hline semi-professionals & $0.416^{* * *}$ & $0.26-0.664$ & $0.260^{* *}$ & $0.112-0.605$ & 0.759 & $0.328-1.753$ \\
\hline employees in services & $0.495^{* *}$ & $0.313-0.782$ & $0.355^{* *}$ & $0.165-0.764$ & 0.949 & $0.411-2.191$ \\
\hline agricultural workers & $0.357^{* * *}$ & $0.195-0.654$ & $0.365^{*}$ & $0.144-0.925$ & 0.101 & $0.003-3.518$ \\
\hline skilled workers & $0.635^{* *}$ & $0.469-0.860$ & $0.407^{* * *}$ & $0.254-0.654$ & 1.089 & $0.338-3.511$ \\
\hline \multicolumn{7}{|l|}{ non-skilled workers (ref.) } \\
\hline \multicolumn{7}{|l|}{ Employment } \\
\hline unemployed & $2.162^{* * *}$ & $1.627-2.873$ & $2.690^{* * *}$ & $1.793-4.036$ & $2.565^{* *}$ & $1.378-4.777$ \\
\hline \multicolumn{7}{|l|}{ Age } \\
\hline $50-64$ years & $1.742 * * *$ & $1.277-2.378$ & 0.903 & $0.557-1.465$ & 0.763 & $0.388-1.501$ \\
\hline $40-49$ years & $2.413^{* * *}$ & $1.73-3.367$ & $1.763^{*}$ & $1.097-2.832$ & 0.840 & $0.385-1.831$ \\
\hline $30-39$ years & $1.988^{* * *}$ & $1.434-2.755$ & 0.832 & $0.487-1.423$ & 1.814 & $0.978-3.368$ \\
\hline \multicolumn{7}{|l|}{$18-29$ years (ref.) } \\
\hline \multicolumn{7}{|l|}{ Education } \\
\hline university & 0.795 & $0.527-1.201$ & 0.557 & $0.28-1.107$ & 1.263 & $0.548-2.914$ \\
\hline college & $0.672^{*}$ & $0.471-0.959$ & $0.489^{*}$ & $0.275-0.870$ & 0.892 & $0.405-1.963$ \\
\hline vocational & 1.096 & $0.786-1.530$ & 1.022 & $0.618-1.690$ & 0.735 & $0.306-1.764$ \\
\hline primary (ref.) & & & & & & \\
\hline \multirow{2}{*}{\multicolumn{7}{|c|}{$\begin{array}{l}\text { Place of residence } \\
\text { city }\end{array}$}} \\
\hline & & & & & & \\
\hline$>200000$ inhabitants & $1.642 * * *$ & $1.222-2.208$ & $2.244 * * *$ & $1.401-3.595$ & $2.259^{*}$ & $1.18-4.322$ \\
\hline 50 000-200 000 inhabitants & 1.079 & $0.761-1.528$ & 1.305 & $0.73-2.330$ & 2.048 & $1.000-4.193$ \\
\hline$<50000$ inhabitants & $2.023^{* * *}$ & $1.53-2.674$ & $1.983^{* *}$ & $1.239-3.175$ & 1.723 & $0.870-3.414$ \\
\hline rural (ref.) & & & & & & \\
\hline
\end{tabular}

Ref. - reference.

$* \mathrm{p}<0.05 ;{ }^{* *} \mathrm{p}<0.01 ; * * * \mathrm{p}<0.001$.

The OR values and confidence intervals calculated for each category separately.

working conditions and work environments which impose the increased extent of working hours, heavy market competition and individual accountability for work in white- collar professions. Contrary to previous studies [16-19], the authors of this study did not confirm that the occupational position affects women. Although recent data on 
Table 4. Multiple logistic regression for the lifetime prevalence of alcohol use disorders (AUDs) in a representative sample of the Polish population aged 18-64, November 2010-March 2011, Poland

\begin{tabular}{|c|c|c|c|c|c|c|}
\hline \multirow{4}{*}{ Variable } & \multicolumn{6}{|c|}{ Prevalence of AUDs - multiple logistic regression } \\
\hline & \multicolumn{4}{|c|}{$\begin{array}{c}\text { men } \\
(\mathrm{N}=1440)\end{array}$} & \multirow{2}{*}{\multicolumn{2}{|c|}{$\begin{array}{c}\text { women } \\
(\mathrm{N}=1366) \\
\text { lifetime }\end{array}$}} \\
\hline & \multicolumn{2}{|c|}{ lifetime } & \multicolumn{2}{|c|}{ past 12 months } & & \\
\hline & OR & $95 \% \mathrm{CI}$ & OR & $95 \% \mathrm{CI}$ & OR & $95 \% \mathrm{CI}$ \\
\hline \multicolumn{7}{|l|}{ Occupational category } \\
\hline $\begin{array}{l}\text { managers and } \\
\text { professionals }\end{array}$ & $0.383^{* *}$ & $0.194-0.755$ & $0.118^{* *}$ & $0.028-0.500$ & 1.914 & $0.527-6.959$ \\
\hline semi-professionals & $0.394 * * *$ & $0.224-0.691$ & $0.284^{*}$ & $0.106-0.761$ & 0.753 & $0.272-2.081$ \\
\hline employees in services & $0.509^{*}$ & $0.301-0.859$ & $0.332 *$ & $0.134-0.823$ & 0.791 & $0.331-1.890$ \\
\hline agricultural workers & $0.521^{*}$ & $0.272-0.997$ & 0.638 & $0.231-1.763$ & 0.201 & $0.006-7.203$ \\
\hline skilled workers & $0.684^{*}$ & $0.493-0.950$ & $0.398^{* * *}$ & $0.237-0.668$ & - & - \\
\hline $\begin{array}{l}\text { non-skilled workers } \\
\text { (ref. for men) }\end{array}$ & & & & & - & - \\
\hline $\begin{array}{l}\text { skilled and non-skilled } \\
\text { workers (ref. for women) }\end{array}$ & - & - & - & - & & \\
\hline \multicolumn{7}{|l|}{ Unemployment } \\
\hline unemployed & $2.168^{* * *}$ & $1.522-3.087$ & $2.346^{* * *}$ & $1.392-3.954$ & $4.152^{* * *}$ & $1.851-9.313$ \\
\hline \multicolumn{7}{|l|}{ Age } \\
\hline $50-64$ years & 1.469 & $0.984-2.193$ & 0.774 & $0.40-1.496$ & 0.773 & $0.295-2.028$ \\
\hline $40-49$ years & $2.049 * * *$ & $1.354-3.101$ & 1.699 & $0.906-3.185$ & 0.904 & $0.337-2.425$ \\
\hline $30-39$ years & 1.431 & $0.952-2.151$ & 0.568 & $0.278-1.161$ & 1.725 & $0.728-4.086$ \\
\hline 18-29 years (ref.) & & & & & & \\
\hline \multicolumn{7}{|l|}{ Education } \\
\hline university & 1.547 & $0.84-2.848$ & 2.137 & $0.763-5.987$ & 0.962 & $0.204-4.545$ \\
\hline secondary & 0.863 & $0.537-1.388$ & 0.927 & $0.407-2.111$ & 1.136 & $0.289-4.462$ \\
\hline $\begin{array}{l}\text { vocational } \\
\text { primary (ref.) }\end{array}$ & 1.025 & $0.675-1.557$ & 1.812 & $0.918-3.574$ & 0.968 & $0.256-3.658$ \\
\hline \multirow{2}{*}{\multicolumn{7}{|c|}{$\begin{array}{l}\text { Place of residence } \\
\text { city }\end{array}$}} \\
\hline & & & & & & \\
\hline$>200000$ inhabitants & $1.742^{* *}$ & $1.196-2.537$ & $3.406^{* * *}$ & $1.883-6.163$ & $2.277^{*}$ & $1.017-5.103$ \\
\hline $\begin{array}{l}50000-200000 \\
\text { inhabitants }\end{array}$ & 1.099 & $0.727-1.66$ & 0.980 & $0.467-2.056$ & 2.216 & $0.939-5.231$ \\
\hline $\begin{array}{l}<50000 \text { inhabitants } \\
\text { rural (ref.) }\end{array}$ & $1.819^{* * *}$ & $1.286-2.571$ & 1.435 & $0.781-2.636$ & 0.803 & $0.299-2.156$ \\
\hline Nagelkerke's R ${ }^{2}$ & & & & & & \\
\hline
\end{tabular}

${ }^{*} \mathrm{p}<0.05 ; * \mathrm{p}<0.01 ; * * \mathrm{p}<0.001$.

- "Does not apply to the group." 
alcohol-related harm have reported a 2-fold increase in alcohol disability-adjusted life years in women in the past 25 years [38], and an increase has been noted in alcohol consumption in women representing a high socio-economic status $[13,39]$, it can be concluded that this study suggests no existing differences in female AUDs among individual occupational categories.

Although alcohol studies most often conclude that women with a low socio-economic status face a greater risk of alcohol-related consequences, including alcohol dependence [13,40-42], these results show that, while experiencing a relatively low share of AUDs, the risk of alcohol harm in women can be equally distributed in the occupational structure. This can be, to some extent, explained by social control and traditional gender roles in Polish families [43], and in particular in families representing lower social classes. However, it should be emphasized that these findings are preliminary as they are based on a limited number of women in the current study suffering from AUDs.

In comparison to previous studies, the authors confirmed detrimental effects of alcohol in lower occupational positions, in terms of the impact of unemployment on alcohol abuse in men [20]. Studies have shown more harmful consumption patterns among economically disadvantaged men that correlate with blue-collar drinking norms [39,44]. Given that the socio-economic factors comprising the occupational position can lead to increased alcohol-related mortality in lower occupational classes [21], hospital admissions [26], and both short- and long-term harm [25], the results of this study are important for health agencies in an attempt to reduce the socio-economic inequalities in alcohol harm among men. The popular neo-liberal rhetoric of individual responsibility in alcohol prevention can hardly affect representatives of the working class [19]. Therefore, more effective measures should be found in the implementation of alcohol control policies, including reducing alcohol availability and affordability, for exam- ple, the minimum unit pricing which, according to the UK experience, has a substantial impact on reducing alcohol consumption and alcohol harm among low-income drinkers and routine or manual workers [45].

The results of this study suggest that the occupational position may be considered an indicator of a social class. However, the authors were not able to confirm the role of income in the stratification pattern.

It has to be emphasized that the study had several limitations. First, the survey questions concerning AUD diagnoses exhibit a non-response bias due to a number of refusals from potential respondents. Second, the AUD diagnoses were based on self-reported symptoms which might have led to underreporting some diagnoses. Third, the data on the gross household income were largely underreported (only $31 \%$ of the respondents provided information on their income) and, therefore, excluded from the set of explanatory variables. This was the major drawback of the study as income is usually considered a key factor in any studies exploring the effects of socio-economic standing. Fourth, although within the EZOP study several data that have potential confounding effects on the outcome variable were collected (e.g., the number of children in a household, or mental and somatic disorders), the authors decided to utilize only selected socio-demographic variables that are most often employed in investigating the effects of socio-economic standing. Considering the above, the results of this study should be interpreted with some caution. These findings should be also further investigated to test whether the data that have been reported reflect the true effect of the occupational structure.

\section{CONCLUSIONS}

This study shows that the occupational position affects the prevalence of AUDs in men, while it has no impact on AUDs in women. Men representing higher occupational classes suffer from AUDs to a lesser extent than those representing lower categories. The findings of the study 
support further development of the concept of the occupational position in alcohol research and offer a new lens with which public health professionals and decision-makers can see the "old" issue of the social class impact on alcohol problems.

This study suggests a number of opportunities for future research including detailed income and household data to explore the subject in more detail, and to understand how the exposure to socio-economic disadvantages and its occupational context may increase the risk of AUDs and contribute to harmful alcohol consumption practices. Moreover, the problem of alcohol harm among women with a high socio-economic status should be further explored, preferably with regard to drinking patterns.

\section{REFERENCES}

1. World Health Organization. Alcohol in the European Union. Consumption, harm and policy approaches. Copenhagen: WHO Regional Office for Europe; 2012.

2. World Health Organization. Status report on alcohol consumption, harm and policy responses in 30 European countries 2019. Copenhagen: WHO Regional Office for Europe; 2019.

3. Świątkiewicz G. [The prevalence of alcohol related disorders]. In: Moskalewicz J, Kiejna A, Wojtyniak B, editors. [Mental health in Poland. Report from the study Epidemiology of psychiatric disorders and access to psychiatric health care EZOP Poland]. Warsaw: Institute of Psychiatry and Neurology; 2012. p. 254-61. Polish.

4. Świątkiewicz G, Moskalewicz J. Changing definitions of the drug problem: an analysis of Polish newspapers in 1985 and the 1990-1993 period. In: Lagerspetz M, editor. Social problems in Newspapers. Study around the Baltic Sea. Helsinki: Nordic Council for Alcohol and Drugs; 2004. p. 105-20.

5. Bujalski M, Hellmann M, Moskalewicz J, Beccaria F, Rolando S. Depoliticising addiction: Who gets to speak in European press reporting, 1991-2011? Nordic Stud Alcohol Dr. 2018;35:52-68, https://doi.org/10.1177/1455072517753558.
6. Room R. Addiction and personal responsibility as solutions to the contradictions of neoliberal consumerism. In: Bell K, McNaughton D, Salmon A. editors. Alcohol, Tobacco and Obesity. Morality, mortality and the new public health. New York: Routledge; 2011. p. 47-59.

7. Blomqvist J, Raitasalo K, Melberg HO, Schreckenberg D, Peschel C, Klingemann J, et al. Popular images of addiction on five European countries. In: Hellman M, Berridge V, Duke K, Mold A, editors. Concepts of addictive substances and behaviours across time and place. Oxford: Oxford University Press; 2016. p. 193-211.

8. Harrison L, Gardiner E. Do the rich really die young? Alcohol-related mortality and social class in Great Britain, 1988-94. Addiction. 1999;94:1871-80.

9. Makela P. Alcohol-related mortality as a function of socioeconomic status. Addiction. 1999;94:867-86.

10. Dietze PM, Jolley DJ, Chikritzhs TN, Clemens S, Catalano P, Stockwell T. Income inequality and alcohol attributable harm in Australia. BMC Public Health. 2009;9, https:// doi.org/10.1186/1471-2458-9-70.

11. Herttua K, Makela P, Martikainen P. Changes in alcoholrelated mortality and its socioeconomic differences after a large reduction in alcohol prices: a natural experiment based on register data. Am J Epidemiol. 2008;168:1110-8, https://doi.org/10.1093/aje/kwn216.

12. Elgar F, Roberts C, Parry-Langdon N, Boyce W. Income inequality and alcohol use: a multilevel analysis of drinking and drunkenness in adolescents in 34 countries. Eur J Public Health. 2005;15:245-50.

13. Bloomfield K, Grittner U, Kramer S, Gmel G. Social inequalities in alcohol consumption and alcohol-related problems in the study countries of the EU concerted action 'Gender, Culture and Alcohol Problems: a Multi-national Study'. Alcohol Alcohol. 2006;41(1):26-36, https://doi.org/10.1093/ alcalc/agl073.

14. Cerda M, Johnson-Lawrence VD, Galea S. Lifetime income patterns and alcohol consumption: investigating the association between long- and short-term income trajectories 
and drinking. Soc Sci Med. 2011;73:1178-85, https://doi. org/10.1016/j.socscimed.2011.07.025.

15. Huckle T, You RQ, Casswell S. Socio-economic status predicts drinking patterns but not alcohol-related consequences independently. Addiction. 2010;105:1192-202, https://doi. org/10.1111/j.1360-0443.2010.02931.x.

16. Casswell S, Pledger M, Hooper R. Socioeconomic status and drinking patterns in young adults. Addiction. 2003;98:60110, https://doi.org/10.1046/j.1360-0443.2003.00331.x.

17. Hart CL, Davey Smith G, Upton MN, Watt GC. Alcohol consumption behaviours and social mobility in men and women of the Midspan Family study. Alcohol Alcohol. 2009;44:332-6, https://doi.org/10.1093/alcalc/agn125.

18. Bloomfield K, Augustin R, Kraus L. Social inequalities in alcohol use andmisuse in the German general population. J Public Health. 2000;8:230-42.

19. McKee M, Pomerleau J, Robertson A, Pudule I, Grinberg D, Kadziauskiene K, et al. Alcohol consumption in the baltic republics. J Epidemiol Commun Health. 2000;54:361-6.

20. Järvinen M. A will to health? Drinking, risk and social class. Health Risk Soc. 2012;14(3):241-56, https://doi.org/10.1080/ 13698575.2012.662632.

21. Maron J, Kraus L, Pogarell O, Gomes de Matos E, Piontek D. Occupational inequalities in psychoactive substance use: A question of conceptualization? Addict Res Theory. 2015;24(3): 186-98, https://doi.org/10.3109/16066359.2015.1093122.

22. Mäkelä P, Herttua K, Martikainen P. The Socioeconomic Differences in Alcohol-Related Harm and the Effects of Alcohol Prices on Them: A Summary of Evidence from Finland. Alcohol Alcohol. 2015;50(6):661-9, https://doi.org/10. 1093/alcalc/agv068.

23. Jones L, Bates G, McCoy E, Bellis MA. Relationship between alcohol-attributable disease and socioeconomic status, and the role of alcohol consumption in this relationship: a systematic review and meta-analysis. BMC Public Health. 2015;15:400, https://doi.org/10.1186/s12889-015-1720-7.

24. Seid AK, Bloomfield K, Hesse M. The relationship between socioeconomic status and risky drinking in Denmark: a cross-sectional general population study. BMC Public Health. 2018;18:743, https://doi.org/10.1186/s12889-018-5481-y.

25. Nielsen MB, Gjerstad J, Frone M. Alcohol use among Norwegian workers: associations with health and well-being. Occup Med. 2018;68:96-8, https://doi.org/10.1093/occmed/ kqy014.

26. Giskess K, Turell G, Bentley R, Kavanagh A. Individual and household-level socioeconomic position is associated with harmful alcohol consumption behaviours among adults. Aust NZ J Publ Health. 2011;35(3):270-7, https://doi. org/10.1111/j.1753-6405.2011.00683.x.

27. Gartner A, Trefan L, Moore S, Akbari A, Paranjothy S, Farewell D. Drinking beer, wine or spirits - does it matter for inequalities in alcohol-related hospital admission? A record-linked longitudinal study in Wales. BMC Public Health. 2019;19;1651, https://doi.org/10.1186/s12889-019-8015-3.

28. Domański H, Sawiński Z, Słomczyński KM. [Sociological Tools Measuring Occupations. New Classification and Scales]. Warsaw: Wydawnictwo IFIS PAN; 2007. Polish.

29. Domański H. [Are there social classes in Poland?]. Warsaw: Wydawnictwo Krytyki Politycznej; 2015. Polish.

30. Słomczyński KM, Janicka K, Tomescu-Dubrow I. On the relationship between class structure and social stratification. Warsaw: Group for Comparative Analysis of Social Inequalities, Institute of Philosophy and Sociology of the Polish Academy of Sciences; 2014. Polish.

31. Domański H, Sawiński Z, Słomczyński KM. [The prestige of professions against the backdrop of social changes 19582008]. Studia Socjol. 2010;4(199):79-119. Polish.

32. Cebula M. [Social determinants of taste and consumption practices. The convergence of social positions and lifestyles or the autonomy of culture?]. Studia Socjol. 2013;2(209):97125. Polish.

33. Domański H, Karpiński Z, Przybysz D, Straczuk J. [Patterns of Eating and the Social Structure]. Warsaw: Wydawnictwo Naukowe Scholar; 2015. Polish.

34. Robins LN, Wing J, Wittchen HU, Helzer JE, Babor FF, Burke A, et al. The Composite International Diagnostic 
Interview: An epidemiologic instrument suitable for use in conjunction with different diagnostic systems and in different cultures. Arch Gen Psychiatry. 1988;45(12):1069-77, https://doi.org/10.1001/archpsyc.1988.01800360017003.

35. Wittchen H-U, Kessler RC, Ustun TB. Properties of the Composite International Diagnostic Interview (CIDI) for measuring mental health outcome. In: Thornicroft G, Tansella M, editors. Mental Health Outcome Measures, Second Edition. London: Gaskell; 2001. p. 212-27.

36. Moskalewicz J, Kiejna A, Wojtyniak B. [Mental health in Poland. Report from the study Epidemiology of psychiatric disorders and access to psychiatric health care - EZOP Poland]. Warsaw: Institute of Psychiatry and Neurology; 2012. Polish.

37. Kiejna A, Adamowski T, Piotrowski P, Moskalewicz J, Wojtyniak B, Świątkiewicz G, et al. [Epidemiology of psychiatric disorders and the availability of psychiatric health care. EZOP - Poland - a research methodology]. Psychiatria Pol. 2015;49(1):5-13, https://doi.org/10.12740/PP/30810. Polish.

38. Wojtyniak B, Goryński P. [Health conditions of the Polish population and its determinants]. Warsaw: National Institute of Public Health - National Institute of Hygiene; 2018. Polish.

39. Sierosławski J. [Psychoactive substances - attitudes and behaviours of Poles]. In: [Alcohol and Society. Attitudes and
Behaviours of Poles toward Alcohol and Alcohol Problems]. Warsaw: Wydawnictwo Edukacyjne PARPA; 2004. p. 11-74. Polish.

40. Mulia M, Schmidt L, Bond J, Jacobs L, Korcha R. Stress, social support and problem drinking among women in poverty. Addiction. 2008;103(8):1283-93, https://doi.org/10.1111/ j.1360-0443.2008.02234.x.

41. Collins SE. Associations between socioeconomic factors and alcohol outcomes. Alcohol Res. 2016;38(1):83-94.

42. Mulia N, Karriker-Jaffe KJ. Interactive influences of neighbourhood and individual socioeconomic status on alcohol consumption and problems. Alcohol Alcohol. 2012;47(2): 178-86, https://doi.org/10.1093/alcalc/agr168.

43. Opora R. [Characteristics of addiction and alcohol abuse in women]. Pol J Soc Reh. 2012;3:317-26. Polish.

44. Room R. Stigma, social inequality and alcohol and drug use. Drug Alcohol Rev. 2005;24:143-55, https://doi.org/10.1080/ 09595230500102434.

45. Holmes J, Meng Y, Meier PS, Brennan A, Angus C, Campbell-Burton A, et al. Effects of minimum unit pricing for alcohol on different income and socioeconomic groups: a modelling study. Lancet. 2014;383:1655-64, https://doi.org/ 10.1016/S0140-6736(13)62417-4.

This work is available in Open Access model and licensed under a Creative Commons Attribution-NonCommercial 3.0 Poland License - http://creativecommons.org/ licenses/by-nc/3.0/pl/deed.en. 